\title{
Can the Social and Cultural Impacts of Ports be Assessed in Terms of Economic Value?
}

\author{
Yen-Chiang $\mathrm{CHANG}^{1}$; Tao $\mathrm{WANG}^{2}$ and Dan $\mathrm{BAI}^{3}$
}

1 School of Law, Shandong University, City of Jinan, Shandong Province, 250100, China

Email: rudieger@hotmail.com; Tel: +86-13020178501.

2 School of Law, Shanghai Maritime University, Shanghai, 201306, China

3 School of Law, Shanghai Maritime University, Shanghai, 201306, China

\begin{abstract}
:
This paper firstly recognises the importance of the port heritage and suggests the economic value of ports can be assessable only if the port heritage is restored to 'economics'. There would not be an economic problem if the port heritage is treated as ethically oriented. This paper then emphasises that the historical heritage element of port is considered to be a common potential to develop tourist activities. The tourist-historic pattern may provide an incentive for other developments which in turn may boost the local economy. As a result, social and cultural impacts of ports can be assessed in terms of economic value through the tourist-historic pattern.
\end{abstract}

Key Words: Maritime Heritage, Economic Value, Maritime Museum, Port Heritage, Geographical Location, Tourist-historic Pattern

\footnotetext{
${ }^{1}$ Dr. Yen-Chiang Chang, LL.M (Taiwan Ocean University, Taiwan); Ph.D (University of Dundee, UK), Associate Professor, School of Law, Shandong University, 250100, China. E-mail:

${ }^{2} \mathrm{Mr}$. Tao Wang is currently reading toward his master's degree at the School of Law, Shanghai Maritime University, 201306, China.

${ }^{3}$ Miss Dan Bai is currently reading toward her master's degree at the School of Law, Shanghai Maritime University, 201306, China.
} 


\section{INTRODUCTION}

The scope of social and cultural sectors of ports is broad and therefore vague in content. In order to consider this issue further, it might be appropriate to start by asking the question 'What does the ocean mean to the United Kingdom?'. Everything, in the briefest possible desired to the question. "The United Kingdom is the greatest maritime nation in the world," a significant amount of people who living in this island will answer this question in a careless, nonunderstanding way (Bullen, 1906, p 303). It is observed that although there is plenty of sentimental interest in the sea, there is a lamentably small amount of practical knowledge of these great matters. It is undoubtedly true that in considering what the sea means to us, marine resources, seaborne trade and other human activities will come to most people's mind. Along with the commercialisation and industrialisation of the global economy, sea-related activities have historically been organised and governed in a separate and distinctive way. Thus, seafarers such as fishing villages, seaborne trade and naval bases are still separate communities.

The aforesaid circumstances will derive a consequence that the sea-related activities were relatively isolated from the land and inevitably leading to differences in traditions and outlook (Smith and Potts, 2005, p 7). More specialised maritime groups have emerged in the current maritime development, such as the leisure industries, offshore oil and gas, marine science, education and marine conservation. All of the aforementioned have bequeathed a strong maritime heritage and tradition in the United Kingdom and elsewhere. This paper firstly recognises the importance of the port heritage and suggests the economic value of ports can be assessable only if the port heritage is restored to 'economics'. This paper then emphasises that the historical heritage element of port is considered to be a common potential to develop tourist activities. The tourist-historic pattern may provide an incentive for other developments which in turn may boost the local economy. As a result, social and cultural impacts of ports can be assessed in terms of economic value through the tourist-historic pattern.

\section{THE MARITIME HERITAGE OF PORTS}

Maritime heritage differs which has emerged from the long sequence of the development path. Navigation and shipping can be traced back to the beginning. Ports, functioning as cargo transfer (Bird, 1971, p 74), did not become meaningful until Roman times (Tuck, 2007, p 27). Shipping together with ports serves as a pivotal use of the sea in various ways. Early stages of the ports' heritage development focus on the realms of heritage conservation projects such as the oldest docks, custom houses and warehouses. At a later stage, attention had been paid to the large-scale urban renewal projects such as London Docklands, the Mersey Docks and Cardiff Bay all of which the port function is largely reduced and replaced by industrial and residential land uses. The ports also provide the primary location for the maritime museums (Smith and Potts, 2005, p 12). For example, the National Maritime Museum at Greenwich, with other notable examples in Liverpool, Newcastle upon Tyne, Aberdeen and others. Another important 
adjunct to the maritime museum is the nation's collection of historic ships such as the Cutty Sark at Greenwich and the Discovery at Dundee. The aforementioned port heritage will in turn generate immense educational and recreational values.

The naval port is another aspect that needs to be addressed. Naval ports have been designed for the defence of the realm and therefore normally have been closely linked with the fortunes of associated port towns. This is mainly due to the need for naval use of maritime space will restrict the local commercial port development (Hoyle and Wright, 1999, p 957). Often, naval ports are geographically quite separate from commercial ports and concentrated in such locations with strategic significance such as: Pembroke Dock, Plymouth, Portsmouth, Chatham, Deptford and Rosyth (Smith and Potts, 2005, p 13). Consequentially, the aforesaid naval ports have stood outside the commercial port system and thus suppressed market economies. It is, however, worth noting that there is an increasing interaction of geopolitical, technological and economic controls over naval ports. This may in turn force governments to economise and induce a shift of emphasis away from the navy in many naval port cities (UK National Audit Office, 1988, p 11).

To this end, it is important to note that "local policy-making on the historic environment takes proper account of the value a community places on particular aspects of its immediate environment." (UK Department of Culture, Media and Sport, 2001, para. 3.16) The character assessment to local authority, therefore, is a useful tool as a way of encouraging greater local involvement in port heritage issues. To consider the aspect of the historic environment in promoting economic, employment and educational opportunities within the local scale is essential when preparing community development strategies (University of Plymouth, 2003, para. 6.11).

\section{THE ECONOMIC VALUE OF PORT HERITAGE}

The oceans have different kinds of economic values, some of which are very difficult or impossible to be quantified. Some marine resources can be quantified and managed in monetary terms, for example, the form of individual transferable quotas has been implemented to manage the fisheries resources. This form of fisheries privatisation means that individual fishers or fishing companies are allocated 'quotas' by the fishery authority. The said quotas may in many ways become fishermen or fishing companies' private property. Based on ownership, fishermen or fishing companies have the rights to exploit certain amount of fisheries resources at their convenience throughout the seasons. This ownership is tradable which means that fishermen or fishing companies are able to sell their quotas or licences (Borgese, 2000, p 767), although this is subject to fisheries legislation. Under the aforesaid circumstances, economic value can be imposed on the fisheries resources. Can the same approach apply to the port heritage? In other words, can port heritage be quantified and expressed in monetary terms? 
There are two prerequisites that need to be considered in order to discuss the economic value of port heritage. Firstly, it is important to recognise that the port heritage exists, which has been discussed earlier in this paper. Secondly, there would not be an economic problem if the port heritage is treated as ethically oriented. This issue will be meaningful only if port heritage is restored to 'economics'. In addressing economic value of port heritage, the alternative is strongly driven towards the latter. Although classical economics comprises only what can be quantified and expressed in terms of pounds or dollars, this view will limit and distort the real wealth of people, of nations and of the world. For example, port heritage comprises social, cultural, geographical and ethical values that are difficult to be quantified and forced into the market system. It can be concluded that when evaluating the economic value of port heritage a certain degree of uncertainty will exist.

Uncertainty may be caused by lack of information and reliable data which may in turn generate risk. The greater the uncertainty, the higher the risk. The degree of risk differs from port to port, as each has its unique regional features and network. The success of the development of port heritage is seen as being very much related to geographical location. Location is relevant to the ports' ability to attract investment, tourists and be in a position to develop commercial port activity. It can be observed that different ports are capable of attracting different types of new business or economic activity. As an official from the Plymouth port authority states that

"I do not feel that waterfront redevelopment involving containers or roll-on/roll-off is possible; it is very difficult to see that we could increase trade because of our geographical location, and even if the dockyard could be used for commercial shipping, it is very difficult to gain access to it, and the only part of the dockyard which could be beneficial to commercial activity, commercial shipping, would be the north end where there is deep water, but of course that is the part the navy would want to retain.” (Hoyle and Wright, 1999, p 976)

This point is further strengthened by a statement made by a Ministry of Defence representative

"Geographical location plays an important part in successful redevelopment. Portsmouth, when looked at in this light, is a straightforward journey from London; Plymouth, whilst it might be straightforward, takes between four and five hours, and Chatham-well, historically it is not regarded as in the main stream of things, and it has got a lot to overcome. Of course three which we generally consider, Portsmouth is rather better placed than the others." (Hoyle and Wright, 1999, p 979)

Although the above examples might not be representative, they demonstrate that the geographical location of the ports combined with their local, regional and historical attributes form a component part of port heritage. All of the abovementioned indicators may in turn determine a port's ability to benefit from any land release and to develop an appropriate programme.

The historical heritage element of a port has immense value for education purposes as, "the fabric of the past constitutes a vast reservoir of knowledge and learning opportunities." 
(University of Plymouth, 2003, para. 6.5) Based on this, ports heritage is considered to be a common potential to develop tourism. The exploitation of the port heritage along with touristhistoric lines may provide an incentive for other developments. Together with the historic buildings, custom houses, warehouse, dockyard, famous maritime events, personalities and ships which will provide a considerable resource for the generation of 'maritime heritage image' and in turn prove influential for external investors. For example, in 1996 Bristol hosted an International Festival of the Sea which was deemed to be the largest maritime festival ever staged in the United Kingdom. The event involved the reorganisation of the material spaces of the host city and promoted Bristol as a 'maritime heritage' landscape (Atkinson and Laurier, 1998, p 199). The long term intention was to attract national and international investment by 'place-marketing' the city as a distinctive location boasting plentiful character and history (Financial Times Bristol, 1994, p I-VIII). The implications of these developments are enormous. "Economically motivated cultural restructuring involves not only a revision of the past, but a deployment in the conflictual space of the society being 'touristified' of desiring and polemical images of identity and alterity in the future.” (Morris, 1995, p 183)

It can be predicted that marketing and subsequent management are critical parts of evaluating the economic value of port heritage. The shift in emphasis from the port heritage to the tourist attraction is seen as allowing a variety of new business and local taxpayers to contribute to the local fiscal base and thus strengthen the local economy. Overall, it would be appear that port heritage is perceived as beneficial to the local community. Diversification is seen as an inherent component of port heritage so that the port city does not have to rely on one major employer. There is a need to market and manage port heritage in order to ensure the success of this scheme. In an environmental connotation covering both human actions and environmental consequences, it comprises both "a series of technical and generally well defined measures governing physical interactions between human activities and marine environment; and [...] a general management dimension encompassing co-ordination of technical management measures, organisational decision-making, policy and strategic planning aspects." (Smith and Potts, 2005, p 14)

\section{CONCLUSION}

Can the social and cultural impacts of ports be assessed in terms of economic value? Yes, they can, although this is difficult. This paper suggests that social, cultural, geographical and ethical values are component parts of the port heritage which are difficult to quantify and be encapsulated into the market system. In order to evaluate the economic value of ports, port heritage has to be restored to 'economics'. This paper also suggests that tourist-historic pattern is one of the approaches which can encourage developers or investors to explore the potential business of port heritage. Since the port heritage has a strong link to local character, the development of the port heritage will in turn strengthen the local economy. Marketing and managing port heritage is a way to ensure the success of tourist-historic scheme. Port heritage is a record of the human use of the sea in all its diversity over a range of time scales. 
Furthermore, 'maritime heritage image' itself has become a major economic resource, not only in what remains and continues to develop in specialist maritime communities, but also in the museums, archives, restoration and elsewhere which forms the basis of the educational and recreational purposes.

\section{ACKNOWLEDGMENTS}

The field work for this research was supported by the projects entitled, 'The Governance of the Marine Environment Across the Taiwan Strait', Institute of Marine Development, Ocean University of China, Research fund issue number: AOCQN200910; 'The Promotion of the Relationship Across the Taiwan Strait based on the Cooperation Efforts on Ocean Governance', Shanghai Municipal Education Commission, Research fund issue number: 10YZ122.

\section{REFERENCES}

Atkinson, D. \& Laurier, E. 1998. A sanitised city? Social exclusion at Bristol's 1996 international festival of the sea. Geoforum 29/2.

Bird, J. 1971. Seaports and seaport terminals. London: Hutchinson.

Borgese, E.M., 2000. The economics of the common heritage. Ocean \& Coastal Management 43.

Bullenm F.T. 1906. Our heritage the sea. London:John Murray.

Financial Times Bristol, 29th November 1994, I-VIII.

Hoyle, B. \& Wright, P.1999. Towards the evaluation of naval waterfront revitalisation: comparative experiences in Chatham, Plymouth and Portsmouth, UK. Ocean \& Coastal Management 42.

Morris, M.1995. Life as a tourist object in Australia. In M.F. Lanfant, J.B. Allcock \& E.M.Bruner (eds.). International Tourism, Identity and Change. London: Sage.

Smith, H.D. \& Potts, J.S. 2005. Managing Britain's marine and coastal environment-toward a sustainable future. London and New York: Routledge.

Tuck, S.J.2007.Socio-economic aspects of commercial ports and wharves in southwest England: a grounded theory approach to regional competitiveness. Doctor of Philosophy Thesis, Business School, Faculty of Social Science \& Business, University of Plymouth.

UK National Audit Office, Ministry of Defence. 1988. Transfer of the royal dockyards to commercial management.

UK Department of Culture, Media and Sport. 2001. The historic environment: a force for our future. University of Plymouth, Noss-on-dart feasibility study. 2003. 